\title{
Production-Use Water Pricing and Corporate Water Use in China: An Evolutionary Game Theory Model
}

\author{
Yao Xiao, ${ }^{1,2}$ Qiao Peng $\mathbb{D}^{2,3}$ Wanting Xu $\mathbb{D}^{1,2}$ and Hongye Xiao ${ }^{4,5}$ \\ ${ }^{1}$ Center for Innovation and Development studies, Beijing Normal University, Zhuhai 519000, China \\ ${ }^{2}$ Economics and Resource Management, Beijing Normal University, Beijing 100875, China \\ ${ }^{3}$ Beijing Key Lab of Study on Sci-tech Strategy for Urban Green Development, Beijing Normal University, Beijing 100875, China \\ ${ }^{4}$ School of economics, Henan University, Kaifeng 475001, China \\ ${ }^{5}$ School of Statistics, Tianjin University of Finance and Economics, Tianjin 300204, China \\ Correspondence should be addressed to Qiao Peng; 201731410009@mail.bnu.edu.cn and Wanting Xu; 202031410004@ \\ mail.bnu.edu.cn
}

Received 20 November 2020; Revised 22 December 2020; Accepted 2 January 2021; Published 12 January 2021

Academic Editor: Chonghui Zhang

Copyright (c) 2021 Yao Xiao et al. This is an open access article distributed under the Creative Commons Attribution License, which permits unrestricted use, distribution, and reproduction in any medium, provided the original work is properly cited.

Decisions related to pricing production-use water are a critical issue that local governments in China are facing. Its significance has increased in recent years, as a serious corporate water-supply shortage has surfaced with rapid economic development and urbanization. Different from developed countries, the pricing of production-use water is a complex issue in China that involves the distribution of benefits among local governments, water-supply companies, and water-consuming companies, where the overall balance is affected by every slight adjustment. Based on the evolutionary game theory, this study constructs an evolutionary game model involving water-supply companies and water-consuming companies with a systematic analysis of the interaction process between the policy formulation related to water pricing by water-supply companies and the decision making related to water consumption by water-consuming companies. The research finds that the difficulty of balancing corporate financial benefits and public water conservation benefits has led to the complexity of water pricing. Moreover, raising water prices will not necessarily cause companies to save water, but it will increase the production cost of the entire economy. This is the direct cause of low water prices, implemented by water-supply companies, in many regions of China.

\section{Introduction}

China is a water-scarce country, with their per capita water resources being only one-fourth of the world average. With the acceleration of economic growth and urbanization, the gap between water supply and demand is further widening $[1,2]$. In the face of increasingly severe pressure for water, the Chinese government is promoting green development strategies to reduce the intensity of water use and promote water recycling [3, 4], and water conservation projects are being constructed widely to facilitate efficient water supply. Nevertheless, the problem remains only partially solved, as the abovementioned policies mostly act on the macrolevel and cannot address inefficiency in corporate water use. At present, every 10,000 USD increase in the Chinese economy costs as much as $1456 \mathrm{~m}^{3}$ of water [1]. Therefore, it is urgently important to maximize the role of water pricing in resource distribution and use price tools to boost the efficient use of water.

A number of studies have shown that low water prices are the key reason for China's current low-efficient water use $[5,6]$. However, many local governments and water-supply companies persistently implement low water prices [7]. This can be explained by the particularity of water resources, as water pricing for corporate use is not only related to enterprise production but also fundamental to social stability and national security. In developed countries such as Europe and the United States, the price of water for corporate use is mainly decided by market mechanisms [8]. For example, the United States does not have a unified regulatory body for 
water prices, and adjustments are performed by the market. Different water-supply organizations adopt different pricing models according to market demand, and one water-supply organization can adopt a variety of price strategies for different types of users. In the United Kingdom, pricing of corporate-use water is also decided by market supply and demand under the input-output model with a price ceiling set by the government. France and other countries have adopted similar pricing methods. Water pricing in China, however, is approved by the government after being determined collaboratively by local water-supply companies, administrative bodies of water resources at all levels, and pricing and finance departments [9]. Water-supply companies are incapable of setting prices by market demand alone. Therefore, mutual influence exists between the decision making of water-supply companies and the watersaving strategies of water-consuming companies, as shown in Figure 1.

When setting water prices, water-supply companies must consider both their own financial benefits and public welfare. That is, they must simultaneously play both corporate and government roles. Meanwhile, their water price policy directly affects the water costs of water-consuming companies, which are, in turn, reflected in water-saving strategies. When making water-saving decisions, local water-consuming companies primarily consider their own benefits and give less consideration to public welfare. Saving water not only reduces water costs for the companies but also serves the public interest, providing both social and environmental benefits $[10,11]$. As the latter is also a goal for water-supply companies, their water conservation strategies impact the water pricing decisions of water-supply companies. Therefore, we can observe the mutual influence between the water pricing strategies of water-supply companies and the conservation strategies of water-consuming company. Moreover, due to information asymmetry, either the water-supply side or the waterconsumer side can predict the actions of the other. As a result, either side can only make profit-maximizing decisions based on their predictions of the other's actions, and they can continue to improve such predictions by learning from the actual results, which then become references for future decision making. Such information asymmetry and the mutual influence of behavioral decision making has undoubtedly increased the complexity and uncertainty of water pricing and corporate water-saving decision making. Therefore, the interests of all stakeholders must be fully considered, and in-depth research be conducted. As an important tool for studying the decision-making behavior of multiple stakeholders in a complex and uncertain environment, evolutionary game theory provides an effective analysis framework for studying the pricing of water resources and corporate water-saving strategies.

In recent years, natural resources and environmental issues have become further complicated, as the decisionmaking process has begun to involve multiple subjects [12-14]; this has led to the wide application of evolutionary game theory in the field. Cai et al.[15], Zhang et al.[16], Troeva et al.[17], Jiang et al.[18], and others adopted evolutionary game methods to study the effects of pollution control by polluter companies under government supervision. Maezuru [19], Li et al.[20], Zhao [21], and Niu et al.[22] used evolutionary game tools in their research of the thirdparty governance model of environmental pollution. $\mathrm{Lu}$ et al.[23], Lu, S. B et al. [24], Fang et al.[25], and Lu et al.[26] applied evolutionary game theory to study cross-regional water pollution control issues. Filho et al.[27] and Xin et al.[28] used game theory methods to investigate the impact of water rights prices on the water-saving strategies of water-consuming companies. Some scholars have also studied how to improve the efficiency of the green supply of upstream corporations under environmental supervision [29-32]. Also applying evolutionary game theory, Chen [33] studied the issue of ecological and environmental protection in tourist destinations. Xin and Li [34] adopted the traditional duopoly game model in their study of the water price game in coastal irrigation areas in free market environments, as well as the impact of water price on the efficiency of agricultural irrigation.

Unlike the market-based pricing mechanisms of developed countries, the pricing of corporate water use in China is mainly negotiated between water-supply companies and the relevant government departments. The addition of the government as a decision-making agent has diversified the roles and goals of water-supply companies, further complicating the pricing process of corporate water use in China at the regional level. Through a review of the relevant literature, we find that a few scholars have employed evolutionary game methods to investigate the issue of regional pricing in corporate water use and companies' water-saving strategies in China. This study is innovative in its attempt to adopt evolutionary game theory to build an evolutionary game model of the water pricing and water-saving strategies adopted by water-supply companies and water-consuming companies, respectively. It analyzes the relationship between water pricing, set by local Chinese water-supply companies and the water conservation strategies of water-consuming companies; here, evolutionary game theory will demonstrate its the advantages in solving complex decision-making problems with multiple agents. In the end, the study explains the recent persistence of low pricing strategies in some regions of China in order to provide references for researching the pricing and consumption decisions of other resources, as well as China's green development.

\section{Methods}

Evolutionary game is a recent development of game theory. Originating in the field of biology, it was first proposed by Smith et al.[35] when studying symmetric population games; they claim that the basic concept of evolutionary game is the evolutionarily stable strategy (ESS). Evolution game theory abandons the hypothesis of hyperrationality found in classical game theory and replaces it with the assumption of bounded rationality. By combining the equilibrium analysis in classical game theory with the dynamic evolution analysis in biology, the evolutionary game theory is established. Evolutionary game is a formal model that places the 


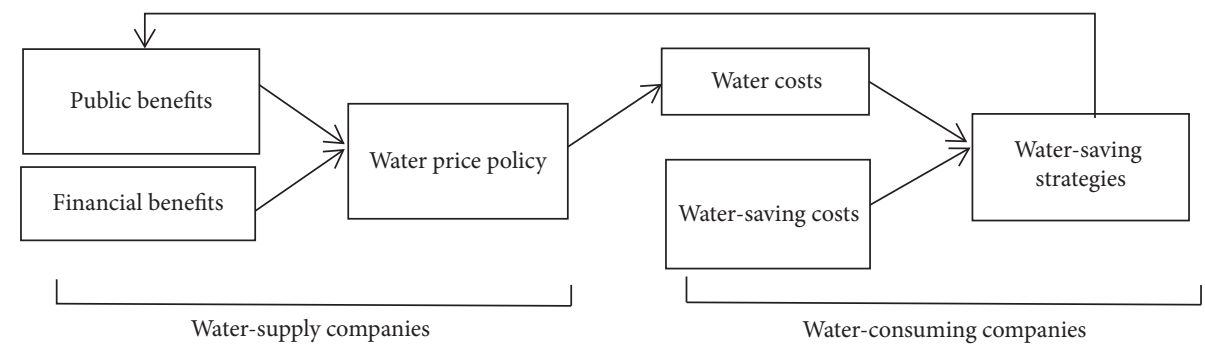

FIGURE 1: Diagram of the relationship between the pricing strategies of water-supply companies and the conservation strategies of waterconsuming companies.

interaction between individuals under the context of evolution [36]. The behavior of an individual is determined by the type of gene, and individuals with different gene types show different behaviors. For example, individuals with combative "eagle" genes and those with mild "doves" genes make different choices when competing for food (that is, fight or concession), and these genotypes can be passed on to the next generation. Individuals with a certain gene type behave accordingly and reap certain benefits that represent their level of adaptation in the natural environment. The greater the benefits, the greater their likelihood of survival in the environment (i.e., through natural selection) and the higher their probability of passing the genotype on to the next generation. That is, the gene fittest for survival will be passed on, while the unfit genes are gradually eliminated, finally resulting in a stable state where biological evolution is achieved. The retained genotypes and their behavioral strategies are, thus, called evolutionarily stable strategies.

In its subsequent development, evolutionary game theory has received extensive attention from the scientific community and is applied in the research of other fields, especially in the social sciences [37]. In the 1990s, economists and social scientists applied biological evolutionary game theory to the research of social problems, and they made particular breakthroughs in the study of the transformation of social systems, the formation of social habits, and social governance. Economists use the ideas mentioned above to study the decision making of multiple interacting microagents in an uncertain environment. The gene type is replaced with the type of strategy that the participant can choose; the level of adaptation is replaced by the amount of benefit of a strategy chosen by the participant; and natural selection is replaced by the principle of bounded rational individuals chasing maximum benefits as the determinant of the probability of a certain strategy being chosen by an individual. The greater the benefit of a strategy is, the higher its probability of being rechosen; this concept corresponds to "heredity" in biology. Participants constantly adjust their strategies according to the size of benefits offered, to the point where all participants finish with the adjustment process with only one strategy retained: the ESS. This strategy can resist the disturbance of any strategy adopted by the participants and restore itself to the original evolutionarily stable state. Evolutionary game theory differs from classical game theory in that it focuses on the dynamic adjustment process of the strategies by individuals with bounded rationality in uncertain environments. It assumes that the participant is not a hyperrational individual with infinite reasoning ability, and unlike classical game, it does not see the participant as capable of achieving the Nash equilibrium strategy through calculation and making choices accordingly. Rather, it is through the process of incessantly repeating the game that the participant learns from the results, adjusts their strategies, and gradually narrows their choices to a stable Nash equilibrium strategy.

In evolutionary game theory, the mode of learning or the strategy adjustment of the participant mainly follows the replicator dynamic equation proposed by Taylor et al.[38]. That is, game participants with bounded rationality adopt the replicator dynamic equation to adjust their strategies. The basic assumption is that the growth rate of the probability of a strategy being adopted is proportional to its level of adaptation. The ESS is obtained by solving a differential equation, and the dynamic equation can be expressed as follows $[39,40]$.

$$
F\left(x_{v}\right)=\frac{\mathrm{d} x_{v}}{\mathrm{~d} t}=x_{v}\left[E\left(x_{v}\right)-\bar{E}\right]
$$

$x_{v}$ is the probability of a strategy being adopted by the game participant, $E\left(x_{v}\right)$ is the expected benefit of adopting the $v$ strategy, and $\bar{E}$ is the average benefit the participant gains when adopting all possible strategies.

\section{Model Construction and Solution}

3.1. Hypotheses and Construction. This paper adopts reduction in water consumption per unit of output of water-consuming companies to indicate water-saving behavior and uses $\alpha$ as the water consumption coefficient. The water-consuming company decides whether to adopt water-saving technologies based upon water prices and water-saving costs, which correspond to the two water consumption coefficients of $\alpha_{1}$ and $\alpha_{2}$, respectively, representing a non-water-saving strategy and a water-saving strategy, with $\alpha_{1}>\alpha_{2} . P_{1}$ and $P_{2}$, respectively, represent the low-price and high-price strategies of the water-supply companies, with $P_{1}<P_{2}$. Table 1 shows all the combinations of the four strategies adopted by water-consuming companies and water-supply companies. To build a concise and realistic game model, we make the following assumptions, based on actual situations.

Hypothesis 1. Water-consuming companies pursue maximum corporate benefit. As water pricing is subject to the 
TABLE 1: Game model of water-consuming companies and water-supplying companies.

\begin{tabular}{lcc}
\hline Water-consuming companies & Low water price $(y) P_{1}$ & Water-supply companies \\
& $U_{1}^{u}=Y_{1}-C-P_{1} W_{1}$ & High water price $(1-y) P_{2}$ \\
\hline Non-water-saving $(x)\left(\alpha_{1}\right)$ & $U_{1}^{s}=P_{1} W_{1}$ & $U_{3}^{u}=Y_{2}-C-P_{2} W_{3}$ \\
\hline Water saving & $U_{3}^{s}=P_{2} W_{3}-L(\Delta P)+g\left(W_{1}-W_{3}\right)$ \\
$(1-x)\left(\alpha_{2}\right)$ & $U_{2}^{u}=Y_{1}-C-P_{1} W_{2}-f(\Delta \alpha)$ & $U_{4}^{u}=Y_{2}-C-P_{2} W_{4}-f(\Delta \alpha)$ \\
& $U_{2}^{s}=P_{1} W_{2}+g\left(W_{1}-W_{2}\right)$ & $U_{4}^{s}=P_{2} W_{4}+g\left(W_{1}-W_{4}\right)-L(\Delta P)$ \\
\hline
\end{tabular}

regulations of local government, water-supply companies assume certain social responsibilities and, therefore, pursue the maximum sum of corporate profits and social benefits.

Hypothesis 2. Taking the non-water-saving, low water price combination strategy as the baseline, the reduction $(\Delta W)$ in water consumption can bring social benefits $g(\Delta W)$. We assume that the revenue function $g(\Delta W)$ is a linear increasing function, and $g(\Delta W=0)=0$. Water-consuming companies need an investment $f(\Delta \alpha)$ in water-saving technologies, where $\Delta \alpha=\alpha_{1}-\alpha_{2}$ represents the advancement of water-saving technologies. $f_{1}>0$ indicates that the more advanced the water-saving technologies are, the greater the cost; $f \prime \prime>0$ indicates the increasing marginal cost of water-saving technologies; and $f(\Delta \alpha=0)=0$ indicates that the cost of investment is 0 when a water-consuming company does not adopt any advanced water-saving technologies.

Hypothesis 3. When water-supply companies raise water prices, the increase in water costs will have a certain impact on the local economy, resulting in a decline in total economic output. Therefore, this study assumes that increasing water prices will cause a loss $L(\Delta P)$ to the entire economy, $\Delta P=P_{2}-P_{1} . L \prime>0$ indicates that the greater the increase in water prices is, the stronger the impact on the economy; $L \prime \prime<0$ indicates that diminishing marginal effect of the changes in water price changes.

Hypothesis 4. A water-consuming company's decision on adopting water-saving technologies is not only dependent on the costs of water and water-saving technologies but also on the costs of other production factors. Since the latter is not the major focus of this study, we assume that the costs (C) of other factors of production remain unchanged.

Hypothesis 5. Water-consuming companies adopt nonwater-saving strategies with a probability of $x$ and watersaving strategies with a probability of $(1-x), 0<=x<=1$. Water-supply companies adopt low-price strategies with a probability of $y$ and high-price strategies with a probability of $(1-y), 0<=y<=1$.

Suppose $\quad W_{1}=\alpha_{1} Y_{1}, \quad W_{2}=\alpha_{2} Y_{1}, \quad W_{3}=\alpha_{1} Y_{2}, \quad$ and $W_{4}=\alpha_{2} Y_{2}$, respectively, represent the water consumption under four strategy combinations (i.e., [non-water-saving, low water price]; [water saving, low water price]; [non-water-saving, high water price]; and [water saving, high water price]). Based on the abovementioned assumptions, we can calculate the corresponding benefits under different combinations of strategies adopted by water-consuming companies and water-supply companies, as shown in Table 1 . As $\alpha_{1}>\alpha_{2}$ and $Y_{1}>Y_{2}$, we have $W_{1}>W_{2}>W_{4}$ and $W_{1}>W_{3}>W_{4}$.

3.2. Model Solution and Analysis. According to Table 1, we can obtain the dynamic replicator equations of water-consuming companies and water-supply companies:

(1) Let $U_{\alpha_{1}}^{u}$ denote the expected benefit when the waterconsuming company adopts

non-water-saving strategies; let $U_{\alpha_{2}}^{u}$ denote the expected benefit when the water-consuming company adopts water-saving strategies; let $U^{u}$ denote the average expected benefit of the water-consuming company.

Expected benefits of water-consuming companies when adopting non-water-saving strategies:

$$
U_{\alpha_{1}}^{u}=y U_{1}^{u}+(1-y) U_{3}^{u}
$$

Expected benefits of water-consuming companies when adopting water-saving strategies:

$$
U_{\alpha_{2}}^{u}=y U_{2}^{u}+(1-y) U_{4}^{u} .
$$

Average expected benefits of water-consuming companies:

$$
U^{u}=x U_{\alpha_{1}}^{u}+(1-x) U_{\alpha_{2}}^{u} .
$$

The dynamic replicator equation of water-consuming companies:

$$
\begin{aligned}
\frac{\mathrm{d} x}{\mathrm{~d} t}= & x\left(U_{\alpha_{1}}^{u}-U^{u}\right)=x(1-x)\left(U_{\alpha_{1}}^{u}-U_{\alpha_{2}}^{u}\right) \\
= & x(1-x)\left\{f(\Delta \alpha)-P_{2}\left(W_{3}-W_{4}\right)\right. \\
& \left.+y\left[P_{2}\left(W_{3}-W_{4}\right)-P_{1}\left(W_{1}-W_{2}\right)\right]\right\}
\end{aligned}
$$

As the dynamic replicator equation of water-consuming companies becomes stable, that is, when $(\mathrm{d} x / \mathrm{d} t)=0$

$$
\begin{aligned}
& x_{1}^{*}=0, \\
& x_{2}^{*}=1, \\
& y^{*}=b=\frac{P_{2}\left(W_{3}-W_{4}\right)-f(\Delta \alpha)}{P_{2}\left(W_{3}-W_{4}\right)-P_{1}\left(W_{1}-W_{2}\right)} .
\end{aligned}
$$


(2) Let $U_{P_{1}}^{s}$ denote the expected benefit when the watersupply company adopts low-price strategies; let $U_{P_{2}}^{s}$ denote the expected benefit when the water-supply company adopts high-price strategies; and let $U^{s}$ denote the average expected benefit of the watersupply company. Expected benefits of water-supply companies when adopting low-price strategies are

$$
U_{P_{1}}^{g}=x U_{1}^{g}+(1-x) U_{2}^{g} .
$$

Expected benefits of water-supply companies when adopting high-price strategies:

$$
U_{P_{2}}^{g}=x U_{3}^{g}+(1-x) U_{4}^{g} .
$$

Average expected benefits of water-supply companies:

$$
U^{g}=y U_{P_{1}}^{g}+(1-y) U_{P_{2}}^{g}
$$

The dynamic replicator equation of water-supply companies:

$$
\begin{aligned}
\frac{\mathrm{d} y}{\mathrm{~d} t}= & y\left(U_{p_{1}}^{g}-U^{g}\right)=y(1-y)\left\{L(\Delta P)-g\left(W_{2}-W_{4}\right)\right. \\
& +\left(P_{1} W_{2}-P_{2} W_{4}\right)+x\left[g\left(W_{2}-W_{4}\right)\right. \\
& +\left(P_{2} W_{4}-P_{1} W_{2}\right)-\left(P_{2} W_{3}-P_{1} W_{1}\right) \\
& \left.\left.-g\left(W_{1}-W_{3}\right)\right]\right\} .
\end{aligned}
$$

As the dynamic replicator equation of water-supply companies becomes stable, that is, when $(\mathrm{d} y / \mathrm{d} t)=$ $0, y_{1}^{*}=0$, and $y_{2}^{*}=1$,

$$
x^{*}=a=\frac{-L(\Delta P)+g\left(W_{2}-W_{4}\right)+\left(P_{2} W_{4}-P_{1} W_{2}\right)}{g\left(W_{2}-W_{4}\right)+\left(P_{2} W_{4}-P_{1} W_{2}\right)-g\left(W_{1}-W_{3}\right)-\left(P_{2} W_{3}-P_{1} W_{1}\right)} .
$$

From the analysis mentioned above, we can observe that when $0<a<1$ and $0<b<1$, the equilibrium points of the two-dimensional dynamic system composed of the water price strategies of water-supply companies and the water-saving strategies of water-supply company are, respectively, $(0,0),(0,1),(1,0),(1,1)$, and $(a, b)$.
3.3. Analysis of Evolutionary Equilibrium Stability. Let $F(x)=(\mathrm{d} x / \mathrm{d} t)$ and $G(y)=(\mathrm{d} y / \mathrm{d} t)$. We use the Jacobian matrix to analyze the stability of each local equilibrium point of the two-dimensional dynamic system:

$$
\begin{aligned}
J= & {\left[\begin{array}{l}
\frac{\partial F(x)}{\partial x} \frac{\partial F(x)}{\partial y} \\
\left.\frac{\partial G(y)}{\partial x} \frac{\partial G(y)}{\partial y}\right]
\end{array}\right]=\left[\begin{array}{cc}
c_{11} & c_{12} \\
c_{21} & c_{22}
\end{array}\right], } \\
c_{11}= & (1-2 x)\left\{f(\Delta \alpha)-P_{2}\left(W_{3}-W_{4}\right)+y\left[P_{2}\left(W_{3}-W_{4}\right)-P_{1}\left(W_{1}-W_{2}\right)\right]\right\}, \\
c_{12}= & x(1-x)\left[P_{2}\left(W_{3}-W_{4}\right)-P_{1}\left(W_{1}-W_{2}\right)\right], \\
c_{21}= & y(1-y)\left[g\left(W_{2}-W_{4}\right)+\left(P_{2} W_{4}-P_{1} W_{2}\right)-\left(P_{2} W_{3}-P_{1} W_{1}\right)-g\left(W_{1}-W_{3}\right)\right], \\
c_{22}= & (1-2 y)\left\{L(\Delta P)-g\left(W_{2}-W_{4}\right)+\left(P_{1} W_{2}-P_{2} W_{4}\right)+x\left[g\left(W_{2}-W_{4}\right)\right.\right. \\
& \left.\left.+\left(P_{2} W_{4}-P_{1} W_{2}\right)-\left(P_{2} W_{3}-P_{1} W_{1}\right)-g\left(W_{1}-W_{3}\right)\right]\right\} .
\end{aligned}
$$

The stable equilibrium point of the dynamic replicator equation must satisfy the following two conditions:

$$
\begin{aligned}
\operatorname{tr}(J) & =c_{11}+c_{22}<0, \\
\operatorname{det}(J) & =c_{11} c_{22}-c_{12} c_{21}>0 .
\end{aligned}
$$

To simplify the expression and make the economic implication more obvious, we carry out the following transformation:

(1) Suppose $\Delta \pi_{1}=P_{1}\left(W_{1}-W_{2}\right)$ and $\Delta \pi_{2}=P_{2}\left(W_{3}-\right.$ $\left.W_{4}\right)$, respectively, denote the situations of low water price $P_{1}$ and high water price $P_{2}$, where water costs 
drop for water-consuming companies owing to the adoption of water-saving technologies that reduces water consumption

(2) Suppose $\Delta g_{1}=g\left(W_{1}-W_{3}\right)$ and $\Delta g_{2}=g\left(W_{2}-W_{4}\right)$, respectively, denote the situations of water-consuming companies not adopting water-saving technologies $\alpha_{1}$ and adopting water-saving technologies $\alpha_{2}$, where water consumption drops due to an increase in water price by water-supply companies, which, in turn, increases public benefit

(3) Suppose $\Delta z_{1}=P_{2} W_{3}-P_{1} W_{1}$ and $\Delta z_{2}=P_{2} W_{4}-$ $P_{1} W_{2}$, respectively, denote the situations of waterconsuming companies not adopting water-saving technologies $\alpha_{1}$ and adopting water-saving technologies $\alpha_{2}$, where water-supply companies gain more corporate benefit

We can obtain Table 2 from the Jacobian matrix of the dynamic replicator equation.

We can know from Table 2 and the stability condition of the dynamic replicator's equation that first, when $\Delta \pi_{1}<f(\Delta \alpha)<\Delta \pi_{2}$ and $\Delta g_{1}+\Delta z_{1}<L(\Delta P)<\Delta g_{2}+\Delta z_{2}$, the binary differential dynamic system composed of water-supply companies and water-consuming companies has two stable equilibrium points, as shown in Figure 2, which are $\mathrm{O}(0,0)$ and $\mathrm{B}(1,1)$, and a saddle point exists as $\mathrm{H}(\mathrm{a}, \mathrm{b})$, of which

$$
\begin{aligned}
& a=\frac{-L(\Delta P)+\Delta g_{2}+\Delta z_{2}}{\Delta g_{2}+\Delta z_{2}-\Delta g_{1}-\Delta z_{1}}, \\
& b=\frac{\Delta \pi_{2}-f(\Delta \alpha)}{\Delta \pi_{2}-\Delta \pi_{1}} .
\end{aligned}
$$

The game between water-supply companies and water-consuming companies on water price and water-saving may eventually converge to the equilibrium point of $\mathrm{O}(0,0)$ or $\mathrm{B}(1,1)$. The respective probabilities are as follows:

$$
\begin{aligned}
P_{o} & =S_{\mathrm{OAHC}}=\frac{1}{2}(a+b) \\
& =\frac{1}{2}\left(\frac{-L(\Delta P)+\Delta g_{2}+\Delta z_{2}}{\Delta g_{2}+\Delta z_{2}-\Delta g_{1}-\Delta z_{1}}+\frac{\Delta \pi_{2}-f(\Delta \alpha)}{\Delta \pi_{2}-\Delta \pi_{1}}\right),
\end{aligned}
$$

$P_{B}=1-S_{\mathrm{OAHC}}$

Conclusion 1: The probability $P_{B}$ that the decisionmaking adjustments of water-supply companies and waterconsuming companies converge to the equilibrium point of B $(1,1)$ is inversely proportional to $\Delta g_{2}, \Delta z_{2}, \Delta g_{1}$, and $\Delta z_{1}$ and directly proportional to $L(\Delta P)$.

The economic implication is that when water-supply companies raise the price of water, the smaller the increase in the corporate benefit of revenue and the public benefit of water saving, the more likely that the evolutionary game converges to the strategy combination of [no water saving, low water price]. Meanwhile, the greater the impact that increasing the price of water has on the economy, the more likely that the evolutionary game converges to the strategy
TABle 2: The Jacobian matrix of the equilibrium points.

\begin{tabular}{lcccc}
\hline $\begin{array}{l}\text { Equilibrium } \\
\text { points }\end{array}$ & $c_{11}$ & $c_{12}$ & $c_{21}$ & $c_{22}$ \\
\hline$(0,0)$ & $f(\Delta \alpha)-\Delta \pi_{2}$ & 0 & 0 & $L(\Delta P)-\Delta g_{2}-\Delta z_{2}$ \\
$(0,1)$ & $f(\Delta \alpha)-\Delta \pi_{1}$ & 0 & 0 & $-\left[L(\Delta P)-\Delta g_{2}-\Delta z_{2}\right]$ \\
$(1,0)$ & $-\left[f(\Delta \alpha)-\Delta \pi_{2}\right]$ & 0 & 0 & $L(\Delta P)-\Delta g_{1}-\Delta z_{1}$ \\
$(1,1)$ & $-\left[f(\Delta \alpha)-\Delta \pi_{1}\right]$ & 0 & 0 & $-\left[L(\Delta P)-\Delta g_{1}-\Delta z_{1}\right]$ \\
$(\mathrm{a}, \mathrm{b})$ & 0 & $c_{12}^{*}$ & $c_{21}^{*}$ & 0 \\
\hline
\end{tabular}

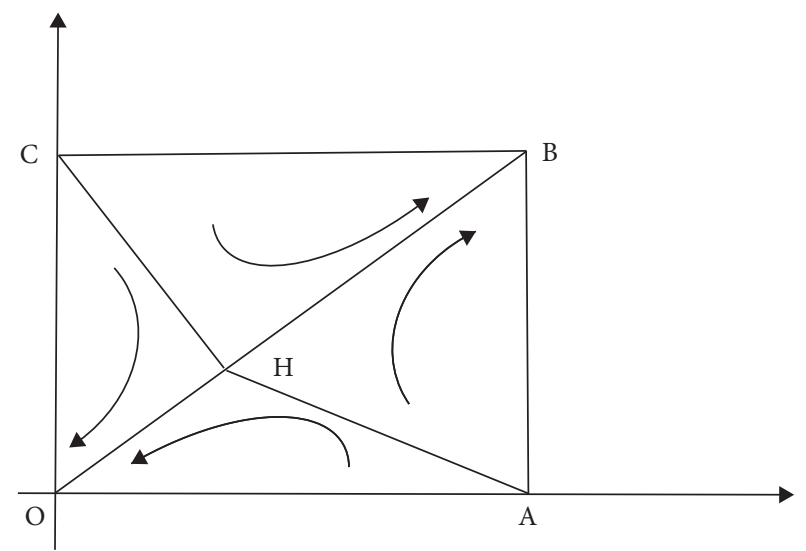

FIgURE 2: Phase diagram of the evolution of decision making between water-consuming and water-supplying companies.

combination of [no water-saving, low water price], and vice versa.

Conclusion 2: The probability $P_{B}$ that the decisionmaking adjustments of water-supply companies and waterconsuming companies converge to the equilibrium point of $\mathrm{B}(1,1)$ is inversely proportional to $\Delta \pi_{2}$ and $\Delta \pi_{1}$ and directly proportional to $f(\Delta \alpha)$.

The economic implication is that when water-consuming companies adopt water-saving technologies, the smaller the decrease in water costs and the higher the cost of water-saving technologies, the more likely that the evolutionary game converges to the strategy combination of [no water-saving, low water price], and vice versa.

Second, when $\Delta \pi_{2}<f(\Delta \alpha)<\Delta \pi_{1}$ and $\Delta g_{2}+\Delta z_{2}<L$ $(\Delta P)<\Delta g_{1}+\Delta z_{1}$, the binary differential dynamic system composed of water-supplying companies and water-consuming companies has two stable equilibrium points, as shown in Figure 3, which are A $(1,0)$ and $C(0,1)$, and a saddle point exists as $H(a, b)$. Due to the rarity of the strategy combinations of [water-saving, low water price] or [non-water-saving, high water price] in real life, this article does not go further into their discussions.

In general, the analysis explains why the state of equilibrium (i.e., [non-water-saving, low water prices]) exists in certain regions. This is because increases in water prices made by water-supply companies have a strong impact $L(\Delta P)$ on the economy; however, they have insufficient corporate benefits and public benefits of water conservation. This leads to the persistence of low pricing strategies by some local water-supply companies, for fear they will lose benefits by raising water prices. 


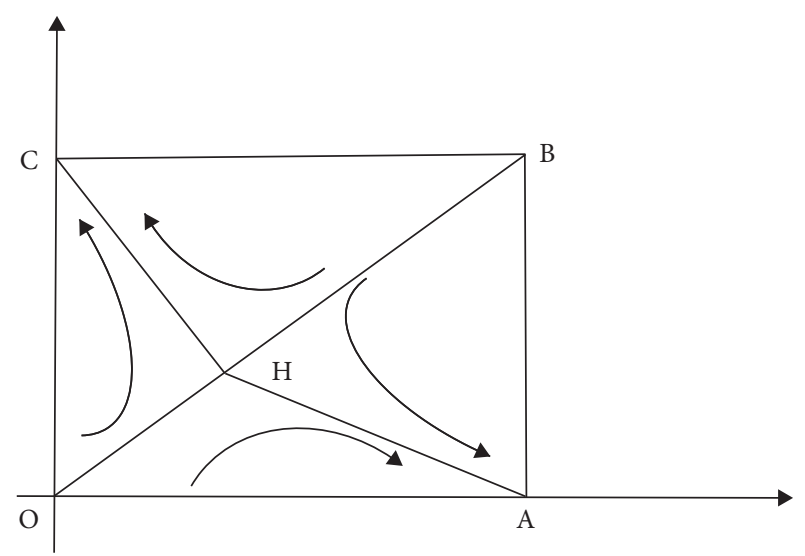

FIgURE 3: Phase diagram of decision-making evolution between water-consuming and water-supplying enterprises.

According to the water price data of water-supply companies in various regions of China [2], it is found that China's Inner Mongolia, Shanxi, and Hebei provinces implement the low water price policy.Water resources of these regions are relatively scarce. Although high water price can improve the efficiency of water use and promote enterprises to save water and, thus, improve the overall social public benefits, since the cost of water-saving technologies $f(\Delta \alpha)$ is relatively high in these areas and they are not adopted by water-supply companies, which high water price cannot greatly promote enterprises to save water, it can only slightly increase the public benefit of water saving. Moreover, higher water prices increase the cost of production, so local governments and the water sectors continue to keep water prices low based on the tradeoff between cost and benefit.

\section{Conclusions and Suggestion}

This study adopts the evolutionary game methodology of biology to create an evolutionary game model of water-supply companies and water-consuming companies. It presents a systematic analysis of the decisionmaking process regarding water pricing and water consumption and explains the low water price strategies in some regions in China. Based on these, the article reaches the following conclusions:

(1) Through an analysis of the persistence of low water price strategies in many regions in China using our evolutionary game model, we find the model is an efficient tool in describing the decision-making process of multiple interacting microagents, especially for decision making in uncertain environments by individuals with bounded rationality. This research shows that water-supply companies and water-consuming companies are related stakeholders and entities with bounded rationality. Moreover, they are unsure about each other's decisions and must constantly adjust their own strategies accordingly. Evolutionary games capture the complexity, uncertainty, and dynamics of the decision-making process of water-supply companies and water-consuming companies by employing dynamic replicator equations. Its unique advantages are proven.

(2) The greater the corporate benefit and public benefit are when water-supply companies raise water prices, and the smaller its impact on the economy and the more likely that the evolutionary game converges to the strategy combination of [water-saving, high water price]. Otherwise, it is more likely for it to converge to the strategy combination of [non-water-saving, low water price].

(3) The greater the decrease in water costs is when water-consuming companies adopt water-saving technologies and the lower their cost, the more likely that the evolutionary game converges to the strategy combination of [water-saving, high water price]. Otherwise, it is more likely for it converge to the strategy combination of [non-water-saving, low water price].

Conclusions (2) and (3) show that even when water-supply companies and the government raise water prices, water-consuming companies will still shrink from adopting water-saving technologies due to their huge costs. As a result, high water price will neither improve water conservation nor boost water efficiency; instead, it will adversely reduce the public benefit of water-supply companies brought by water-supply companies and further inhibit them from raising the price of water. However, when the cost of water-saving technologies is low, raising water prices will have an immediate effect; that is, water-consuming companies will start saving water. Nevertheless, only when their impact on the economy is limited will water-supply companies willingly choose high water prices, thus improving water conservation and boosting water efficiency.

Therefore, this article suggests that when watersupply companies and the government are considering promoting water conservation by raising water prices, they can provide relevant policy support, such as preferential subsidies or tax reductions, to water-consuming companies to soothe the induced economic impact. The government can also provide targeted subsidies to waterconsuming companies that are investing in water-saving technologies, thus encouraging innovations in watersaving technologies and, thereby, enhancing water conservation through pricing.

\section{Data Availability}

The data used to support the findings of this study are included within the article.

\section{Conflicts of Interest}

The authors declare that there are no conflicts of interest regarding the publication of this paper. 


\section{Acknowledgments}

This paper was supported by the Institute of National Accounts (Zhuhai), Beijing Normal University. This research was funded by the National Natural Science Foundation of China (Grant no. 71873019) and the National Social Science Fund of China (Grant no. 18ZDA123).

\section{References}

[1] W. Fang, S. Huang, G. Huang et al., "Copulas-based risk analysis for inter-seasonal combinations of wet and dry conditions under a changing climate," International Journal of Climatology, vol. 39, no. 4, pp. 2005-2021, 2018.

[2] S. Liu, S. Huang, Y. Xie et al., "Identification of the non-stationarity of floods: changing patterns, causes, and implications," Water Resources Management, vol. 33, no. 3, pp. 939-953, 2018.

[3] J. Chang, A. Guo, Y. Wang et al., "Reservoir operations to mitigate drought effects with a hedging policy triggered by the drought prevention limiting water level," Water Resources Research, vol. 55, no. 2, pp. 904-922, 2019.

[4] Y. Shang, P. Hei, S. Lu et al., "China's energy-water nexus: assessing water conservation synergies of the total coal consumption cap strategy until 2050," Applied Energy, vol. 210, pp. 643-660, 2018.

[5] J. Zhao, H. Ni, X. Peng, J. Li, G. Chen, and J. Liu, "Impact of water price reform on water conservation and economic growth in China," Economic Analysis and Policy, vol. 51, pp. 90-103, 2016.

[6] J. Li and X. C. Ma, "Econometric analysis of industrial water use efficiency in China," Environment Development and Sustainability, vol. 17, no. 5, pp. 1-18, 2015.

[7] L. Mu, C. Wang, B. Xue, H. Wang, and S. Li, "Assessing the impact of water price reform on farmers' willingness to pay for agricultural water in northwest China," Journal of Cleaner Production, vol. 234, pp. 1072-1081, 2019.

[8] G.. G.. Rojas and R. Hilda, "Water price policy and its institutional role as an economic instrument for water management," Water Policy in Mexico, vol. 20, pp. 137-152, 2019.

[9] Z. Chen, H. Wang, and X. Qi, "Pricing and water resource allocation scheme for the south-to-north water diversion project in China," Water Resources Management, vol. 27, no. 5, pp. 1457-1472, 2013.

[10] W. Wang, H. Xie, N. Zhang, and D. Xiang, "Sustainable water use and water shadow price in China's urban industry," Resources Conservation \& Recycling, vol. 128, pp. 489-498.

[11] World Bank, "China country water resources partnership strategy (2013-2020)," World Bank Other Operational Studies, vol. 50, no. 3, pp. 133-139, 2013.

[12] S. Zeng, Y. Hu, T. Balezentis, and D. Streimikiene, "A multicriteria sustainable supplier selection framework based on neutrosophic fuzzy data and entropy weighting," Sustainable Development, vol. 28, no. 5, pp. 1431-1440, 2020.

[13] S. Zeng, X. Peng, T. Baležentis, and D. Streimikiene, "Prioritization of low-carbon suppliers based on Pythagorean fuzzy group decision making with self-confidence level," Economic Research-Ekonomska Istraživanja, vol. 32, no. 1, pp. 1073-1087, 2019.

[14] C. Zhang, C. Chen, D. Streimikiene, and T. Balezentis, "Intuitionistic fuzzy MULTIMOORA approach for multicriteria assessment of the energy storage technologies," Applied Soft Computing, vol. 79, pp. 410-423, 2019.
[15] L.-ru. Cai, H.-wei. Wang, and W.. Zeng, "Mixed-strategy game simulation on environmental pollution based on system dynamics," in Proceedings of the Control \& Decision Conference, pp. 2199-2204, IEEE, Yantai, Shandong, China, July 2008.

[16] X.. Zhang, Q.. Li, and J.. Yao, Study on Secondary Lead Enterprises Pollution Monitoring with an Asymmetric Evolutionary Game Model, pp. 1-4, World Automation Congress, Taipei, Taiwan, 2012.

[17] M. Troeva and V. Lukin, "On a game-theoretic model of environmental pollution problem," Advances in Dynamic Games, pp. 223-236, 2013.

[18] K. Jiang, D. You, R. Merrill, and Z. Li, "Implementation of a multi-agent environmental regulation strategy under Chinese fiscal decentralization: an evolutionary game theoretical approach," Journal of Cleaner Production, vol. 214, pp. 902-915, 2019.

[19] M. Maezuru, "Stochastic differential game of transboundary pollution and international environmental policy," Studies in Regional Science, vol. 40, no. 2, pp. 413-425, 2010.

[20] H.. Li, "Genlong. Guo, "A differential game analysis of multipollutant transboundary pollution in river basin," Physica A: Statistical Mechanics and Its Applications, vol. 535, p. 12248, 2019.

[21] Y. Zhao, "Government's control countermeasures against environmental pollution by introducing third-party constraints," Nature Environment and Pollution Technology, vol. 19, no. 02, pp. 571-576, 2020.

[22] X. Niu, X. Wang, J. Gao, and X. Wang, "Has third-party monitoring improved environmental data quality? An analysis of air pollution data in China," Journal of Environmental Management, vol. 253, Article ID 109698, 12 pages, 2020.

[23] S. Lu, H. Bao, and H. Pan, "Urban water security evaluation based on similarity measure model of vague sets," International Journal of Hydrogen Energy, vol. 41, no. 35, pp. 15944-15950, 2016.

[24] S. Lu, Y. Shang, and Y. Li, "A research on the application of fuzzy iteration clustering in the water conservancy project," Journal of Cleaner Production, vol. 151, pp. 356-360, 2017.

[25] W. Fang, S. Z. Huang, K Ren et al., "Examining the applicability of different sampling techniques in the development of decomposition-based streamflow forecasting models," Journal of Hydrology, vol. 568, pp. 534-550, 2019.

[26] S. Lu, X. Wu, H. Sun, W. Li, and Y. Tang, "The multi-user evolutionary game simulation in water quality-based water source system," Environmental Geochemistry and Health, vol. 42, no. 3, pp. 863-879, 2020.

[27] F. A. S. Filho, U. Lall, and R. L. L. Porto, "Role of price and enforcement in water allocation: insights from Game Theory," Water Resources Research, vol. 44, no. 12, pp. 12424-12431, 2008.

[28] B. Xin and M. Sun, "A differential oligopoly game for optimal production planning and water savings," European Journal of Operational Research, vol. 269, no. 1, pp. 206-217, 2017.

[29] Q.-h. ZHU and Y.-j. DOU, "Evolutionary game model between governments and core enterprises in greening supply chains," Systems Engineering - Theory \& Practice, vol. 27, no. 12, pp. 85-89, 2007.

[30] S. Barari, G. Agarwal, W. J. Zhang, B.. Mahanty, and M. . K. Tiwari, "A decision framework for the analysis of green supply chain contracts: an evolutionary game approach," Expert Systems with Applications, vol. 39, no. 3, pp. 29652976, 2012. 
[31] P. Ji, X. Ma, and G. Li, "Developing green purchasing relationships for the manufacturing industry: an evolutionary game theory perspective," International Journal of Production Economics, vol. 166, pp. 155-162, 2015.

[32] Y. Tian, K. Govindan, and Q. Zhu, "A system dynamics model based on evolutionary game theory for green supply chain management diffusion among Chinese manufacturers," Journal of Cleaner Production, vol. 80, pp. 96-105, 2014.

[33] Si-hua. Chen, "An evolutionary game study of an ecological industry chain based on multi-agent simulation:A case study of the poyang lake eco-economic zone," Sustainability, vol. 9, no. 7, p. 1165, 2017.

[34] B. Xin and Y. Li, "Bifurcation and chaos in a price game of irrigation water in a coastal irrigation district," Discrete Dynamics in Nature and Society, vol. 201310 pages, 2013.

[35] J. M. Smith and G. R. Price, "The logic of animal conflict," Nature, vol. 246, no. 5427, pp. 15-18, 1973.

[36] J. Smith, Evolution and the Theory of Games, Cambridge University Press, Cambridge, Englang, 1982.

[37] J. Hofoauer and K. Siglnund, "Evolutionary game dynamies," Bulletin-Ameriean Mathematieal Soeiety, vol. 40, no. 4, pp. 479-520, 2003.

[38] P. D. Taylor and L. B. Jonker, "Evolutionary stable strategies and game dynamics," Mathematical Biosciences, vol. 40, no. 12, pp. 145-156, 1978.

[39] Y. Yang and W. Yang, "Does whistleblowing work for air pollution control in China? A study based on three-party evolutionary game model under incomplete information," Sustainability, vol. 11, no. 2, p. 324, 2019.

[40] Q. Peng and Y. Xiao, "Will third-party treatment effectively solve issues related to industrial pollution in China?" Sustainability, vol. 12, no. 18, p. 7685, 2020. 